\title{
Estudo histológico e histoquímico da glândula de Duvernoy de Clelia plumbea (Wied) (Serpentes, Colubridae, Xenodontinae)
}

\author{
Márcia Ferret Renner ${ }^{1}$ \\ Simone Maria Teixeira de Sabóia-Morais ${ }^{2}$
}

\begin{abstract}
Histological and histochemical study of Duvernoy's gland from Clelia plumbea (Wied) (Serpentes, Colubridae, Xenodontinae). There are report two human envenenomations for species from Clelia Fitzinger, 1826 (opisthoglyph snake). The patients exhibited symptoms similar from bothropic accident. Then this work have with objective, the hystological and histochemical study of Duvernoy's gland from Clelia plumbea. For the hystological observation of the Duvernoy's gland were using, with paraffin's cutting edge, two methods: Hematoxylin + Eosin and Toluidine's Blue. With historesine's cutting edge were using three methods: Metilen's Blue, Toluidine's Blue + Floxine and Toluidine's Blue. For the histochemical detection were using six techniques, with paraftin's cutting edge: PAS, PAS + Alcian Blue $\mathrm{pH}$ 2,5, Alcian Blue pH 2,5, PAS + Salivar Amilase, Method of Lars Grimelius and Method of Lillie. It was evidenced the predominance of serous cells on Duvernoy's gland. In relation to the histochemical constituion of the duvernoy's gland, was verified the presence of glucoconjugates neuters, enzymes and cells with reductive activity. By fact from this species to kill his preys by constriction, the predominance of serous cells in the duvernoy's gland, don' $t$ must be direct related with the subjugation of his preys, but with the digestive processes. Histological and histochemical analysis showed cells of Duvernoy's gland are constituted for two populations: serous cells (prodution of enzymes) and mucous cells (prodution of glucoconjugates).

KEY WORDS. Serpentes, Colubridae, Clelia plumbea, Duvernoy's gland, histological, histochemical
\end{abstract}

As serpentes da família Colubridae não apresentam uma glândula de veneno desenvolvida, como as que são encontradas em Elapidae e Viperidae (DATTA \& TU 1993). Entretanto, grande parte das espécies de colubrídeos apresentam a glândula de Duvernoy, que é responsável pela produção de uma secreção serosa (TAUB 1967; DATTA \& TU 1993). Esta glândula localiza-se na região supralabial, posteriormente aos olhos (TAUB 1967; KochVA 1987) e é considerada homóloga à glândula de veneno das serpentes das famílias Atractaspididae, Elapidae e Viperidae (KocHVA 1978). Através da inoculação dessa secreção por meio de dentes aumentados e sulcados existentes na porção posterior das maxilas (dentição opistóglifa), algumas espécies subjugam suas presas pelo envenenamento (RODRÍGUEZ-ROBLES 1994). Existem vários casos de acidentes ofídicos com este grupo de serpentes (MINTON

1) Curso de Pós-graduação em Biociências, Departamento de Biologia, Faculdade de Biociências e Museu de Ciências e Tecnologia, Pontificia Universidade Católica do Rio Grande do Sul. Caixa Postal 1429, 90619-900 Porto Alegre, Rio Grande do Sul, Brasil.

2) Laboratório de Comportamento Celular, Departamento de Morfologia, Campus II, ICB IV, Universidade Federal de Goiás. Caixa Postal 131, 740001-970 Goiânia, Goiás, Brasil. 
1990), inclusive com alguns casos graves e fatais. Devido a importância médica e também evolutiva, alguns estudos foram realizados enfocando a morfologia e composição química da glândula de Duvernoy (e.g. TAuB 1967; GigAX 1971; SAVITZKY 1980; KocHVA 1987).

O gênero Clelia Fitzinger, 1826, compreende nove espécies de serpentes opistóglifas da região Neotropical (ZAHER 1996; FrANCO et al. 1997). Existem dois acidentes ofídicos relatados para espécies deste gênero (CHIPPAUX 1986; PINTO et al. 1991), no qual as vítimas apresentaram sintomas similares ao acidente botrópico. Neste trabalho é apresentado a histologia e histoquímica da glândula de Duvernoy da serpente Clelia plumbea (Wied, 1820).

\section{MATERIAL E MÉTODOS}

Dois espécimes de C. plumbea procedentes do Resgate de Fauna da Usina Hidrelétrica de Serra da Mesa, Minaçu, Goiás, Brasil foram sacrificados. Utilizou-se dose letal de hidrato de cloral (1:10.000). Em seguida através da dissecação, as glândulas de Duvernoy foram retiradas e imersas por duas horas em solução fixadora contendo: aldeído glutárico a $0,25 \%$, paraformoldeído a $4 \%$ em tampão fosfato de sódio $0,1 \mathrm{M}(\mathrm{pH} 7,4)$. A inclusão foi realizada em parafina e historresina. Os cortes em parafina com $6 \mu \mathrm{m}$ espessura e os cortes em historresina com $2 \mu \mathrm{m}$, foram realizados em micrótomo.

Para a observação histológica da glândula de Duvernoy foram utilizados, com cortes em parafina, duas colorações: Hematoxilina + Eosina e Azul de Toluidina. Com cortes em historresina utilizou-se três colorações: Azul de Metileno, Azul de Toluidina + Floxina e Azul de Toluidina.

Para a detecção histoquímica utilizou-se 6 técnicas, com cortes em parafina: PAS (deteç̧ão de glicoconjugados neutros) de acordo com MCMANUS (1946), associação de PAS + Alcian Blue pH 2,5 (detecção de glicoconjugados neutros e ácidos - carboxilados e sulfatados) (LEV \& SPICER 1964), Alcian Blue pH 2,5 (detecção de glicoconjugados ácidos - carboxilados e sulfatados) (LEV \& SPICER 1964), PAS + Amilase salivar (deteç̧ão de glicogênio), Método de Lars Grimelius (detecção de células argirófilas, ricas em enzimas) e Método de Lillie (detecção de locais com atividade redutora).

Todo o registro fotográfico foi realizado em fotomicroscópio.

\section{RESULTADOS}

Histologia. A glândula de Duvernoy é revestida por uma camada de tecido conjuntivo denso onde ocasionalmente encontram-se células fusiformes (Fig. 1). Esta região emite septo fino que envolve e delimita conjuntos celulares, muitos alongados (parecendo túbulos) e alguns arredondados (lembrando ácinos) (Figs 1, 2). Tal estrutura sugere uma organização lobular e uma formação total de lobo.

De acordo com a análise feita das células que constituem esta glândula, observa-se que quanto a forma, as células são piramidais.

A maioria das células são serosas (produção de proteínas e enzimas), ocorrendo algumas células mucosas (produção de glicoconjugados). 

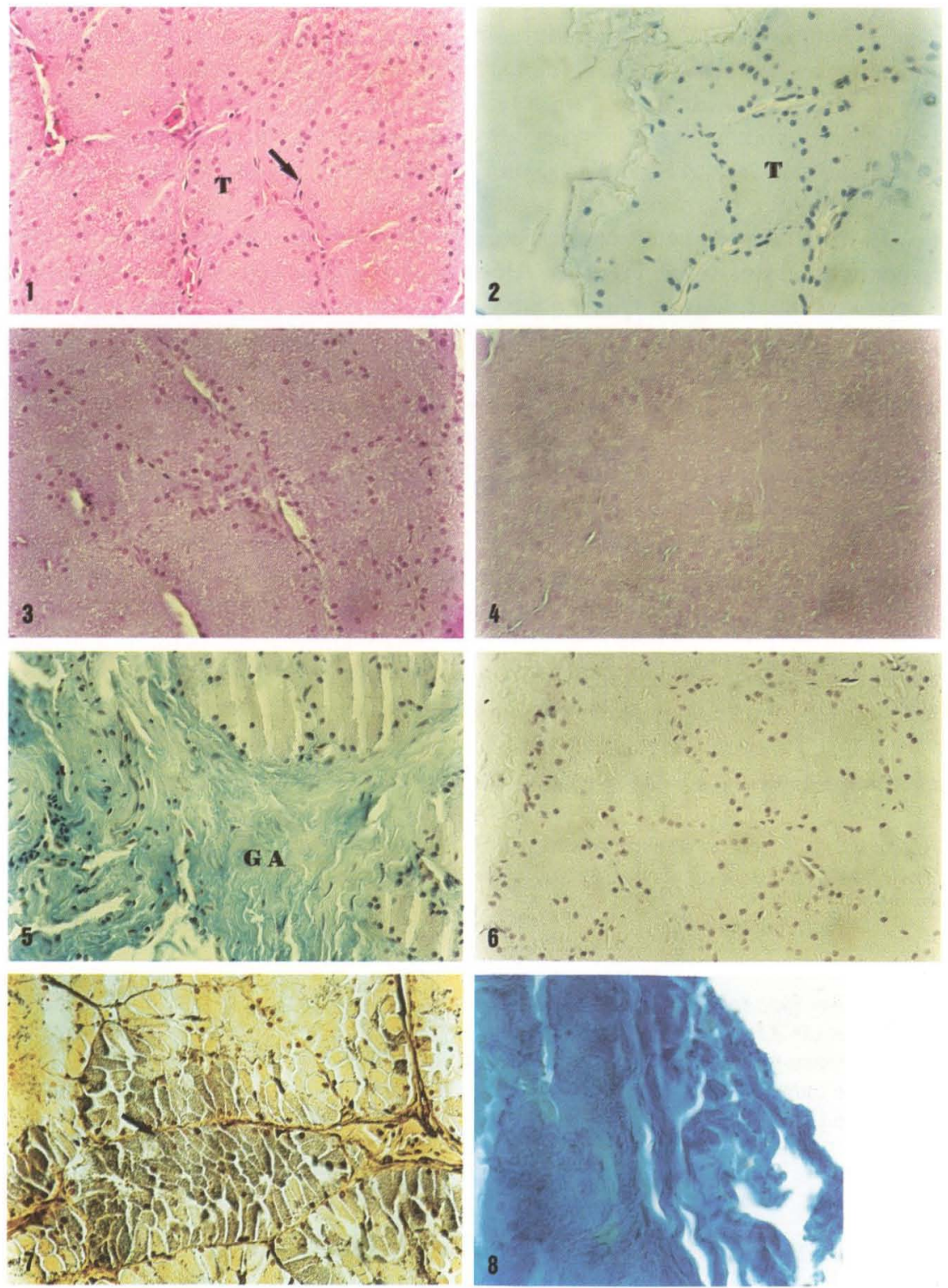

Figs 1-8. Fotomicrografia da glândula de Duvernoy de Clelia plumbea. (1) Célula fusiforme (seta) e túbulo (T), coloração: H.E.; (2) túbulo (T), coloração: Azul de Toluidina; (3) alta taxa de glicoconjudados neutros, técnica: PAS + Hematoxilina; (4) baixa taxa de glicoconjudados ácidos, técnica: PAS + Alcian Blue $\mathrm{pH} 2,5$; (5) positividade apenas no tecido conjuntivo para glicoconjugados ácidos (GA), técnica: Alcian Blue pH 2,5 + Hematoxilina; (6) presença de outros glicoconjugados neutros, o glicogênio não foi revelado nesta reação, técnica: PAS + Amilase salivar + Hematoxilina; (7) células fortemente reativas (seta), técnica: método de Lars Grimelius; (8) células com atividade redutora, técnica: método de Lillie. 
Histoquímica. Os dados obtidos indicam que o conteúdo citoplasmático das células que constituem a glândula de Duvernoy contém glicoconjugados neutros, já que as células são fortemente PAS - reativas (Tab. I, Fig. 3), ou seja, são ricas em grânulos cujo conteúdo possui radicais do grupamento vic-glicol. Quando realiza-se a associação do Alcian Blue pH 2,5 ao PAS observa-se que as células são reativas apenas ao PAS e não apresentam positividade para o Alcian Blue pH 2,5 (Tab. I, Fig. 4), o qual detecta presença de glicoconjugados ácidos, indicados pelos radicais carboxilados e sulfatados. Frente ao Alcian Blue $\mathrm{pH} 2,5$, apenas o tecido conjuntivo é positivo (Tab. I, Fig. 5). Quando em presença da reação PAS + amilase salivar o conteúdo celular é positivo, porém mais fraco quando comparado ao PAS apenas (Tab. I, Fig. 6). Pela reatividade ao PAS + amilase salivar têm-se a indicação que em parte a positividade ao PAS se deve a existência citoplasmática de glicogênio. Tal reação indica que há presença de outros elementos PAS reativos, pois o glicogênio foi quebrado pela amilase salivar, lavado no processamento e portanto não foi revelado nesta ocasião.

As células reativas ao Método de Lars Grimelius apresentam seu conteúdo citoplasmático com gotículas negras bem definidas. Estas células foram observadas nas proximidades de vasos sagüíneos ou ductos e também na superfície da glândula (lóbulo) (Tab. I, Fig. 7). Esta reação tem por objetivo marcar células argirófilas que possuam grânulos ricos em proteínas (enzimas). De acordo com esta reação pode-se constatar a presença de grupos celulares argentafins e não argentafins.

Estas mesmas células também são positivas ao Método de Lillie que revela a presença de células com atividade redutora (Tab. I, Fig. 8).

Tabela I. Dados obtidos através de reações histoquímicas sobre a glândula de Duvernoy de Clelia plumbea. Legenda: Reação positiva (+) fraca, $(++)$ forte; (-) reação negativa.

\begin{tabular}{lc}
\hline \multicolumn{1}{r}{ Técnica Histoquímica } & Reações das células da glândula de Duvernoy \\
\hline PAS & + \\
PAS + Alcian Blue pH 2,5 & + \\
Alcian Blue $\mathrm{pH} 2,5$ & + \\
PAS + Amilase salivar & + \\
Método de Lars Grimelius & + \\
Método de Lillie & + \\
\hline
\end{tabular}

\section{DISCUSSÃO E CONCLUSÕES}

KOCHVA \& GANS (1970) mencionam que as células da glândula de Duvernoy podem ocorrer em formação de ácinos ou túbulos, o que aparece na glândula de Duvernoy de C. plumbea.

A evolução das glândulas de Duvernoy ocorreram em paralelismo e foi alcançada independentemente pelos diferentes grupos de colubrídeos (TAUB 1967). A mesma situação é sugerida para a condição opistóglifa, o qual não forma um grupo natural (KoCHVA 1987; SAVITZKY 1980), de tal forma que, torna-se difícil fazer algumas considerações filogenéticas com os dados obtidos neste estudo. TAUB (1967) descreveu quatro tipos básicos de glândula de Duvernoy em relação a 
histologia. A primeira categoria é a presença de células mucosas na região supralabial, estando ausente a glândula de Duvernoy. A segunda categoria consiste de uma glândula de Duvernoy predominantemente serosa, com células mucosas intercaladas (glândula de Duvernoy mista). A terceira categoria consiste de uma glândula predominantemente mucosa com esparsas células serosas. A quarta categoria é puramente serosa. A glândula de Duvernoy de C. plumbea enquadra-se na segunda categoria, apresentando a maioria das células serosas (produção de proteínas e enzimas), ocorrendo algumas células mucosas (produção de glicoconjugados).

TAUB (1967) afirma que Clelia clelia (Daudin, 1803) possui células puramente serosas. Entretanto, este autor não mencionou qual subespécie (C. c. clelia ou C. c. plumbea), as quais foram elevadas à nível de espécie recentemente (ZAHER 1996).

Foi observado por TAUB (1967), que em colubrídeos que apresentam a glândula de Duvernoy com predominância de células mucosas, estes subjugam suas presas por constrição. Por outro lado, os colubrídeos que apresentam a glândula de Duvernoy com predominância de células serosas, subjugam suas presas pelo envenenamento (TAUB 1967; SAVITSKY 1980; DATTA \& TU 1993).

Na glândula de Duvernoy de C. plumbea ocorre a predominância de células serosas. Pelo fato desta espécie subjugar as suas presas por constrição, as enzimas de seu veneno devem estar primariamente relacionadas com os processos digestivos e não com a subjugação de presas.

A reação ao PAS encontrada nas células da glândula de Duvernoy de $C_{\mathbb{t}}$ plumbea (células com glicoconjugados neutros), também é encontrada em outros colubrídeos: Spalerosophis cliffordi (Schlegel, 1837), Dispholidus typus (Smith, 1829), Natix natrix (Linnaeus, 1758), Philodryas patagoniensis (Girard, 1858), Sibynomorphus mikani (Schlegel, 1837), Philodryas olfersi (Lichtenstein, 1823) e Hydrodynastes gigas (Duméril, Bibron \& Duméril, 1854) (KochVA \& Gans 1970; LOPES et al. 1982; SALOMÃo \& SAWAYA 1989; GLENN et al. 1992).

Em relação à constituição histoquímica da glândula de Duvernoy, foi constatada a presença de glicoconjugados neutros, enzimas e células com atividade redutora. O que sustenta a afirmação de que há ao menos duas populações de células na glândula de Duvernoy, células serosas (produção de enzimas) e células mucosas (produção de glicoconjugados).

AGRADECIMENTOS. Somos gratos ao Prof. Dr. Thales De Lema e a Paulo Sérgio Bernarde pela leitura e sugestões do manuscrito. A Marta R. Magalhães pelo auxílio no sacrifício das serpentes. Ao Prof. Luciano Vannucci da UFG (Laboratório de Microscopia) do Departamento de Biologia Geral, pelo empréstimo do fotomicroscópio.

\section{REFERÊNCIAS BIBLIOGRÁFICAS}

Chippaux, J.P. 1986. Les serpents de la Guyane Française. Coll. Faune Trop., Paris, 27: 1-165.

DatTA, G. \& A.T. Tu. 1993. Toxicology and biochemistry of Colubridae venom. Jour. Toxicol., New York, 12 (1): 63-89.

Franco, F.L.; O.A.V. Marques \& G. Puorto. 1997. Two news species of colubrid snakes of the genus Clelia from Brazil. Jour. Herpetol., St. Louis, 31 (4): 483-490. 
Glenn, J.L.; L.W. Porras; R.D. NohaveC \& R.C. Straight. 1992. Contr. Herpetol., New York, 1992: 19-26.

GyGaX, P. 1971. Entwicklung, Bau und Funktion der Giftdrüse (Duvernoy's gland) von Natrix tesselata. Acta Trop., Amsterdan, 28 (3): 226-274.

Kochva, E. 1978. Oral glands of the Reptilia, p. 43-161. In: C. Gans \& K.A. Gans (Eds). Biology of Reptilia. New York, Academic Press, 8, 782p.

-1987. The origin of snakes and evolution of the venom apparatus. Toxicon, New York, 25 (1): $65-106$.

Kochva, E. \& C. GANs. 1970. Salivary glands of snakes. Clinical Toxicol., New York, 3 (3): 363-387.

LEV, R. \& S.S. SPICER. 1964. Specific staining sulphate groups with alcian blue at low pH. Jour. Histochem. Cytochem., Seatle, 12: 306-309.

Lopes, R.A.; M.G.D. Contrera; J.R.V. Costa; S.O. Petenusci \& J.S. LimA-Verde. 1982. Les glandes salivaires de Philodryas patagonienses Girard, 1857 (Serpentes, Colubridae). Arch. d'Anat. Microscop., Fribourg, 71 (3): 175-182.

McManus, F.F. 1946. A histological demonstration of mucin after periodic acid. Nature 158: 202.

Minton, S.A. 1990. Venomous bites by nonvenomous snakes: an annotated bibliography of colubrid envenomation. Jour. Wilderness, London, Medicine 1: 119-127.

Pinto, R.N.L.; N. JORGE-DA-SiLVA JR. \& S.D. Aird. 1991. Human envenomation by the south american opistoglyph Clelia clelia plumbea (Wied). Toxicon, New York, 29 (12): 1512-1516.

RodRigueZ-RoBles, J.A. 1994. Are the Duvernoy's gland secretions of colubrid snakes venoms? Jour. Herpetol., St. Louis, 28 (3): 388-390.

SAlomÃo, M.G. \& P. SAWAYA. 1989. Fisioecologia, histoquímica e ultraestrutura da glãndula de Duvernoy de Sibynomorphus mikani (Serpentes-Colubridae). Alimentação. An. Acad. Bras. Ci., Rio de Janeiro, 61 (2): 240.

S^vitzky, A.H. 1980. The role of venom delivery strategies in snake evolution. Evolution 34 (6): 1194-1204.

TAUB, A.M. 1967. Comparative histological studies on Duvernoy's gland of colubrid snakes. Bull. Amer. Mus. Nat. Hist. 138: 1-50.

ZAHER, H. 1996. A new genus and species of pseudoboine snake, with a revision of the genus Clelia (Serpentes, Xenodontinae). Boll. Mus. Reg. Sci. Nat. Torino 14 (2): 289-337.

Recebido em 07.IV.1999; aceito em 12.VII. 2000. 